\title{
Efficacy of Interaction among College Students in a Web-Based Environment
}

\author{
Ching-Wen Chang \\ Missouri State University, USA
}

\begin{abstract}
In order to investigate the efficacy of interaction among college students in a Web-based learning environment, three interactive tools (discussion board, e-mail, and online chat) were evaluated regarding the level of interaction and tool preference among a diverse group of college students in terms of age, gender, and online learning experience. A survey instrument was developed and used to assess and encourage interactive qualities in distance courses. A four-factor split-plot ANOVA was applied to analyze the data. The survey's questions were repeated across each of the three tools in order to determine interaction efficacy levels in a Web-based environment. Discussion board, e-mail, and online chat each had statistically significant interactions with one another across four different factors: Instructional Design, Instructor Engagement, Learner Engagement, and Tool Preference. E-mail was the most preferred method of interaction, particularly among younger students. Implications for practice and research are discussed.
\end{abstract}

Keywords: Blackboard Discussion board, Interactions, Web-based Course, Blackboard chat, Blackboard E-mail

\section{Introduction and Literature Review}

As a result of rapid technological changes as well as shifting market conditions, the educational environmenthasaltered a significant portion of its delivery format from traditional face-to-face format to distance education. A wide range of technological options for distance education, including teleconferencing, film, videotape, and computer, are now available to distance educators.

Web-based learning is one of the more recent distance education options in which information is sent and received via the Internet. In Webbased learning, "information is available at any time from any place to any Internet user. This is creating tremendous opportunities for universities to provide a learning environment that is accessible to all" (Aggarwal, 2000, p. 2). Web-based learning increases the opportunity for learners who are unable to return to a traditional program to pursue a degree or finish their uncompleted education because of geographical limitations, time restrictions, or other obligations.

A significant difference between Web-based learning and traditional face-to-face learning is the physical distance between the learners and instructor, as well as between learners. Without a physical connection or interaction, learners need to be highly self-motivated to learn. They also need to be able to learn independently. A flexible study schedule is advantageous because learners can respond to assignments 
and discussions at the most convenient time for them. However, this can also be a drawback for those who have trouble with time management or procrastination. Becker (2001) states that students need a higher level of self-discipline in order to succeed in a Web-based course. Tuckman (2002) indicates that more serious procrastinators possess less self-regulation and, consequently, tend to perform poorly in a Webbased environment.

In addition to the inherent need for more self-discipline, Carlson and Repman (2000) suggest that "once the student decides to take the course and is introduced to the course tools and technologies, the instructor's next challenge is to address the feeling of isolation that comes with distance education" (p. 10). Some Web-based learners become frustrated with distance learning and may fail to complete courses because of the feelings of isolation and lack of interaction. One method of addressing this problem is to introduce interaction into the distance course.

According to Dewey (1916), learning is an activity of performing collective social and interpretive behavior among learners within their environment. The result of these learning actions reflects the active relationship among learners with their ideas, actions, and outcomes. Exchanging activity not only increases learners' motivation, but also promotes critical thinking.

Similarly, Vygotsky (1978) interprets learning as a social process. According to his Social Constructivism theory, cognitive skills and thinking patterns are the outcomes of social activities that occur in the learner's environment. He believes students can only learn when they interact with people in their environment and cooperate with peers. Vygotsky introduced the concept of the zone of proximal development (ZPD), referring to the 'distance' between what a learner can achieve alone and what a learner can achieve under guidance or through interaction with more experienced/capable peers.

Moore and Kearsley (2005) take Vygotsky's (1978) ZPD theory a step further with their concept of transactional distance. Moore and Kearsley define transactional distance as "the physical distance that leads to a communication gap, a psychological space of potential misunderstandings between the instructors and the learners that has to be bridged by special teaching techniques" (p. 224). In transactional distance, dialogue has a growing importance, based on Vygotsky's suggestion that learners use language to construct their thinking. According to Moore (1991), transactional distance increases if dialogue decreases.

A pedagogical model should contain both autonomous and interactive learning and teaching. Ruhleder and Twidale (2000) believe that "the availability of increasingly robust Web-based, networked technologies offers opportunities for creating and sustaining collaborative, reflective learning experiences for a distributed student body" (p. 1).

This study investigated the efficacy of interaction among college students in a Web-based learning environment. If Webbased courses provide learners with effective interaction, then they possess all the benefits that a course could possibly have - flexibility, convenience, and quality. On the other hand, if Web-based learning environments do not initiate adequate interaction, researchers and curriculum designers need to improve Webbased courses so they do facilitate a high level of interaction for distance learners.

Web-based instructional interaction generally occurs in three ways: between the learners and the instructors; between learners; and between learners and content. Therefore, interactive tools 
such as discussion boards, e-mail, and online chat were examined in this study. Interactions were explored to determine whether they varied due to differences in age, gender, and prior online learning experience in terms of (a) the instructional design of a Web-based course, (b) instructor engagement, (b) learner engagement, and (c) preference of use of the interactive tools. Hypotheses of no difference were proposed, therefore, no significant differences were expected between the efficacy of interaction based on age, gender, or prior online learning experience in regard to instructional design, instructor engagement, learner engagement, or interactive tool preference.

\section{Purpose of Study}

The purpose of this study was to investigate the efficacy of interaction among college students in a Web-based learning environment. Because there seems to be much variation in how students and faculty define interaction (see e.g., Roblyer \& Ekhaml, 2000) this study attempts to clarify the role of three specific online communication tools relative to interaction in an online learning environment.

A 16-item questionnaire was developed for this study (see Appendix A). All questions utilized a five-point Likert scale. Questions 1 to 5 requested demographic information. Question 6 assessed which interactive tools (discussion board, e-mail, or online chat) learners felt provided the highest amount of interaction. Questions 7 and 8 were grouped under one dependent variable (Instructor Engagement) and measured the interaction between learners' tool use and instructors' responsiveness. Questions 9,10 , and 11 were grouped under one dependent variable (Learner Engagement) to determine the interaction of learner engagement among peers. Questions 12 through 16 were grouped under one dependent variable (Preference of Tool Use) in order to establish the preference of tool use and effectiveness of the tools. The scoring (measurements) of the variables are explained via the questionnaire itself.

\section{Method}

\subsection{Participants}

The research focused on college students currently or previously enrolled in Web-based courses, regardless of major or student level (e.g., undergraduate or graduate). The survey population was not drawn randomly; rather, snowball sampling was utilized in this study. Selected faculty members were contacted from a list of members of the Society of International Chinese in Educational Technology (SIECT) acquired from the organization's Web site. The purpose of the research was explained before asking for their assistance. The cooperating faculty members were sent the study's questionnaire for distribution to their students. To determine the distribution of samples across participating universities, the total online enrollment for each institution during the 2004 - 2005 academic year was considered. The proportions of total online enrollment were used to determine quotas for the institutions that participated in the study.

\subsection{Instrumentation}

This research study utilized the survey design as described below. The term questionnaire is used in this study in lieu of survey as is often done in survey research to distinguish the design from the data collection tool used for carrying out the research (Glasow, 2005). A cross-sectional survey instrument was developed based on a rubric created by Roblyer and Wiencke (2003) to assess and encourage interactive qualities in distance courses. The cross-sectional survey design, the most popular form of survey design used in education, is used to gather data on a population at a single point 
in time (Creswell, 2005). To facilitate the ease of data collection, the instrument was an online, interactive questionnaire. The questionnaire was tested on a pilot group of participants from a university that did not participate in the actual study. The valid sample size was 19 from 25 sets of feedback. Cronbach's alpha internal consistency reliability was .908 . Based on suggestions from participants in the pilot study, the 16-item questionnaire was refined by clarifying terminology and adjusting the format to improve readability.

In addition to standard demographic data, the questions were grouped into four sections: Instructional Design, Instructor Engagement, Learner Engagement, and Preference of the Tools. The questionnaire primarily focused on two learning content management systems (LCMS) - Blackboard and WebCT - as they were the e-learning tools commonly used at the participating institutions. The LCMS applications contain several collaborative tools for learning; however, this study only considered discussion boards, e-mail, and the virtual classroom, that is, online chat.

\subsection{Procedures}

The questionnaire was distributed to participants from seven universities in the United States considered as peer institutions because of their similar student population size, state-supported status, and availability of active distance education programs. The formal survey instrument was administered over three weeks during a single semester. Participants received an e-mail from their instructors containing a link to the Web-based, interactive questionnaire. Their consent to participate was requested on the first page; consent forms were then e-mailed to the researcher. The electronic data was stored in a Web form database system accessible only by the researcher and provided by the researcher's institution. The questionnaire was anonymous in that names were not associated with the responses.

\subsection{Research Design and Statistical Analysis}

This research study utilized the survey design. Survey research is a pre-experimental, descriptive research method. This design "... consists of two elements - a single instance of a causal event and the assessment of its effects" (Cherulnik, 1983, p. 158). Figure 1 illustrates the research design based upon the notation developed by Campbell and Stanley (1966).

$$
\text { X } \quad \mathrm{O}
$$

Figure 1. The Posttest Only Preexperimental Design $(\mathrm{X}=$ intervention, $\mathrm{O}=$ observation)

Survey research is useful when researchers wish to collect data on phenomena that cannot be directly observed, such as interaction in an online course (Survey Methods, n.d.).

The learner's age, gender, and prior online learning experience, as well as the Web course tool as a repeated measure, were used as independent variables to determine the efficacy of interaction among the four the dependent variables: (a) instructional design, (b) instructor engagement, (c) learner engagement, and (d) preference of tool use. Further, the independent variables were examined to see if they interacted to create differences on the four dependent variables. A four-factor split-plot ANOVA was applied to analyze the data. The four-factor split-plot ANOVA is a combination of the characteristics of one-factor repeated measures and four-factor fixed-effects models. The questions in the instrument were repeated across each of the three tools (discussion board, e-mail, and online chat) in order to determine interaction efficacy levels in a Webbased environment. The effectiveness of each 
Web course tool was examined by calculating the means and standard deviations for each dependent variable.

\section{Results}

\subsection{Demographic Characteristics}

A total of 443 students participated in the study; $26.6 \%$ were male and $73.4 \%$ were female. The participants' age range was between 18 and 59, which was divided into two groups: 18-29 years old (74.1\%), and 30-59 years old (25.9\%). Only two age groups were utilized as the researcher's primary interest in this variable was to compare younger 'digital natives' with older 'digital immigrants' (Prensky, 2001). Online learning experience was represented by the number of online courses that a participant had taken or was taking currently. The range of online learning experience was between 0 and 7 or more courses, which was divided into five groups: 0 courses $(45.7 \%), 1-2$ courses $(27.5 \%)$, 3-4 courses (13.7\%), 5-6 courses (5.2\%), and 7 or more courses $(7.7 \%)$.

\subsection{General Survey Analysis}

The 16 items in the questionnaire were divided into five sections. Questions 1 to 5 were demographic items, including questions about age, gender, and prior online learning experience. Question 6 assessed which interactive tools (discussion board, e-mail, or online chat) learners felt provided the highest amounts of interaction. Most participants agreed that e-mail $(M=3.92, S D=1.14)$ provided the most interaction (see Table 1).

Questions 7 and 8 were grouped under one dependent variable (Instructor Engagement); scores from both questions were computed into one set of data to measure the interaction between learners' tool use and instructors' responsiveness. Again, most participants agreed that e-mail ( $M=4.05, S D=.87)$ provided prompt and quality responses from the instructors compared to other communication tools.

Questions 9, 10, and 11 were grouped under one dependent variable (Learner Engagement); scores were computed into one set of data to determine the interaction of learner engagement among their peers. Participants indicated they gained the most peer interaction through e-mail $(M=3.72, S D=.96)$.

Questions 12 through 16 were grouped under one dependent variable (Preference of Tool Use); scores were computed into one set of data to determine the preference of tool use and effectiveness of the tools. Participants preferred to use e-mail $(M=4.20, S D=.67)$ more than discussion boards and online chat.

Table 1. Descriptive Analysis of Survey Information

\begin{tabular}{|c|c|c|c|}
\hline & & $M$ & $S D$ \\
\hline \multirow{3}{*}{$\begin{array}{l}\text { Instructional } \\
\text { Design }\end{array}$} & Discussion board & 3.37 & 1.25 \\
\hline & E-mail & 3.92 & 1.14 \\
\hline & Online chat & 3.26 & 1.41 \\
\hline \multirow{3}{*}{$\begin{array}{l}\text { Instructor } \\
\text { Engagement }\end{array}$} & Discussion board & 3.69 & 1.09 \\
\hline & E-mail & 4.05 & .87 \\
\hline & Online chat & 3.80 & .96 \\
\hline \multirow{3}{*}{$\begin{array}{l}\text { Learner } \\
\text { Engagement }\end{array}$} & Discussion board & 3.59 & 1.04 \\
\hline & E-mail & 3.72 & .96 \\
\hline & Online chat & 2.90 & 1.20 \\
\hline \multirow{3}{*}{$\begin{array}{l}\text { Preference of } \\
\text { Tool Use }\end{array}$} & Discussion board & 3.96 & .87 \\
\hline & E-mail & 4.20 & .67 \\
\hline & Online chat & 3.40 & .98 \\
\hline
\end{tabular}

\subsection{Instructional Design}

The interaction of instructional design with gender, age, and online learning experience was examined using a four-factor split-plot 
ANOVA. Gender, age, and prior online learning experience were used as between-group variables; the instructional tool, or the one repeated variable, served as the fourth factor.

As shown in Table 2 , there was a statistically significant difference across tools in terms of instructional design; in other words, the three tools provided different levels of interaction, $F(2,260)=5.725, p<.05$. There was a statistically significant interaction between the three tools and age, which indicated that perceptions about the amount of learning interaction varied based on age, $F(2,260)=6.163, p<.05$.

Table 2. ANOVA Summary Table for Significant Effects on Instructional Design of a Web-Based Course by Tool and Age

\begin{tabular}{llll}
\hline & $F$ & $d f$ & $p$ \\
\hline Tool & 5.725 & 2,260 & $.004^{*}$ \\
Tool x Age & 6.163 & 2,260 & $.002^{*}$ \\
\hline
\end{tabular}

$* p<.05$

A post hoc test was performed using paired samples $t$ tests to determine which tools were significantly different from each other. As shown in Table 3, there was a significant difference between the means of discussion board and e-mail, $t(379)=-6.46, p<.001$ and between e-mail and online chat, $t(265)=.29$, $p<.001$. Further, the means of e-mail were higher than the means of discussion board and online chat.

Table 3. Paired Samples $t$ Test among Three Tools for Instructional Design

\begin{tabular}{lclcc}
\hline Pairs & $\begin{array}{c}\text { Mean } \\
\text { Difference }\end{array}$ & $t$ & $d f$ & Sig. \\
\hline DB - EM & -.50 & -6.46 & 379 & $.000^{*}$ \\
DB - OC & .03 & .29 & 265 & .775 \\
EM - OC & .69 & 7.58 & 281 & $.000^{*}$ \\
\hline$* p<.05$ DB = Discussion Board; EM $=$ \\
E-mail; OC = Online Chat
\end{tabular}

Because of the significant interaction between age and instructional tools, the data was analyzed to determine if (a) the tool variable had a statistically significant interaction with each age group, and (b) the age variable had a statistically significant interaction with the individual tools. There was a statistically significant difference between the three tools for learners who were between 18-29 years old, $F(2,260)=6.163, p<.05$. On the other hand, there was no statistically significant difference between the three tools for learners who were between $30-59$ years old, $F(2,63)=1.414, p$ $>.05$.

Paired samples $t$ tests were performed to identify the differences across the repeated measure in the 18-29 age group. As shown in Table 4, there was a statistically significant difference between discussion board and e-mail, $t(271)=-8.58, p<.001$ and between e-mail and online chat, $t(215)=8.04, p<.001$. Additionally, learners in the 18-29 age group thought e-mail provided higher interaction than any other tool.

Table 4. Descriptive Analysis of Three Tools in 18-29 Age Group

\begin{tabular}{l|l|l|l|l}
\hline & & $M$ & $N$ & $S D$ \\
\hline \multirow{2}{*}{$\begin{array}{l}\text { Pair 1 } \\
\text { DB - EM }\end{array}$} & DB & 3.25 & 272 & 1.22 \\
\cline { 2 - 5 } & EM & 4.01 & 272 & 1.08 \\
\hline \multirow{2}{*}{$\begin{array}{l}\text { Pair 2 } \\
\text { DB - OC }\end{array}$} & BD & 3.22 & 200 & 1.20 \\
\cline { 2 - 5 } & OC & 3.29 & 200 & 1.45 \\
\hline \multirow{2}{*}{$\begin{array}{l}\text { Pair 3 } \\
\text { EM - OC }\end{array}$} & EM & 4.13 & 216 & 1.01 \\
\cline { 2 - 5 } & OC & 3.32 & 216 & 1.45 \\
\hline
\end{tabular}

$\mathrm{DB}=$ Discussion Board; $\mathrm{EM}=$ E-mail; $\mathrm{OC}=$ Online Chat

The data was also analyzed using a univariate method. There was a statistically significant difference between age and discussion board, which indicated that learners across age groups felt differently about discussion 
board interaction, $F(1,384)=9.070, p<.05$. The older learners (30-59 years old) rated the amount of interaction through discussion boards as higher than did the younger learners (18-29 years old). For the e-mail tool, there was also a statistically significant difference between age groups, $F(1,428)=18.414, p<$ .05 . The younger learners thought the amount of interaction they experienced through e-mail was higher than the older learners. However, there was no statistically significant interaction between age and online chat use, $F(1,282)=$ $1.791, p>.05$.

\subsection{Instructor Engagement}

Instructor engagement was explored through a repeated measure. As shown in Table 5 , there was a statistically significant difference across tools in terms of instructor engagement; in other words, the three tools provided different levels of instructor engagement, $F(2$, $89)=4.526, p<.05$. A statistically significant interaction between the three tools and age indicated that perceptions about levels of instructor engagement varied based on age, $F(2,89)=3.206, p<.05$.

Table 5. ANOVA Summary Table for Significant Effects on Instructor Engagement by Tool and Age

\begin{tabular}{llll}
\hline & $F$ & $d f$ & $p$ \\
\hline Tool & 4.526 & 2,89 & $.014^{*}$ \\
Tool x Age & 3.206 & 2,89 & $.046^{*}$ \\
\hline
\end{tabular}

${ }^{*} p<.05$

A post hoc test was performed using paired samples $t$ tests to determine which tools were significantly different from each other. As shown in Table 6, there was a significant difference between the means of discussion board and e-mail, $t(306)=-6.73, p<.001$; between e-mail and online chat, $t(95)=7.99$, $p<.049$; and between discussion board and online chat, $t(98)=3.90, p<.001$. The mean of e-mail was higher than the means of discussion board and online chat, while the mean of discussion board was higher than the mean of online chat.

Table 6. Paired Samples $t$ Test among Three Tools for Instructor Engagement

\begin{tabular}{rllll}
\hline Pairs & $\begin{array}{l}\text { Mean } \\
\text { Difference }\end{array}$ & $t$ & $d f$ & Sig. \\
\hline DB - EM & -.38 & -6.73 & 306 & $.000^{*}$ \\
DB - OC & .17 & 1.99 & 95 & $.049^{*}$ \\
EM - OC & .40 & 3.90 & 98 & $.000^{*}$ \\
\hline$* p<.05$ DB = Discussion Board; EM $=$ \\
E-mail; OC = Online Chat
\end{tabular}

Because of the significant interaction between age and instructional tools, the data was also analyzed to determine if (a) the tool variable had a statistically significant interaction with each age group, and (b) the age variable had a statistically significant interaction with the individual tools. There was a statistically significant difference between the three tools for learners in the 18-29 age group, $F(2,56)=$ $12.580, p<.05$. On the other hand, there was no statistically significant difference between the three tools for learners in 30-59 age group, $F(2,33)=1.046, p>.05$.

Paired samples $t$ tests were performed to identify differences across the repeated measure in the 18-29 age group. There was a statistically significant difference between discussion board and e-mail, $t(205)=-6.9, p$ $<.001$; between discussion board and online chat, $t(59)=3.15, p<.003$; and between e-mail and online chat, $t(62)=5.08, p<.001$. In Table 7, the descriptive analysis indicates that learners in the 18-29 age group thought e-mail and discussion board provided higher instructor engagement than online chat. 
Table 7. Descriptive Analysis of Three Tools in 18-29 Age Group

\begin{tabular}{l|l|l|l|c}
\hline & & $M$ & $N$ & $S D$ \\
\hline Pair 1 & DB & 3.62 & 206 & 1.14 \\
\cline { 2 - 5 } DB - EM & EM & 4.11 & 206 & .85 \\
\hline Pair 2 & DB & 4.01 & 60 & .92 \\
\cline { 2 - 5 } DB - OC & OC & 3.67 & 60 & 1.02 \\
\hline \multirow{2}{*}{$\begin{array}{l}\text { Pair 3 } \\
\text { EM - OC }\end{array}$} & EM & 4.30 & 63 & .73 \\
\cline { 2 - 5 } & OC & 3.67 & 63 & 1.02 \\
\hline
\end{tabular}

$\mathrm{DB}=$ Discussion Board; $\mathrm{EM}=\mathrm{E}-\mathrm{mail} ; \mathrm{OC}=$ Online Chat

The data was also analyzed using a univariate method. There was no statistically significant difference between age and discussion board, indicating that learners in both age groups felt similarly about discussion boards in terms of instructor engagement, $F(1,319)=3.475, p>$ .05 . There was also no statistically significant difference between age and e-mail, $F(1,408)=$ $.282, p>.05$ or between age and online chat, $F(1$, $100)=3.368, p>.05$, indicating that both age groups felt similarly about these instructional tools in relation to instructor engagement.

\subsection{Learner Engagement}

A four-factor split-plot ANOVA was applied to analyze the data in regard to learner engagement. The questions in the instrument were repeated across each of the three tools (discussion board, e-mail, and online chat) in order to determine interaction efficacy in a Web-based environment. As shown in Table 8, there was a statistically significant difference among tools in terms of learner engagement; in other words, the three tools provided different levels of interaction, $F(2,94)=10.907, p<.05$. There was no statistically significant interaction between the repeated measure and any of the other three between-subjects variables in terms of learner engagement.
Table 8. ANOVA Summary Table for Significant Effects on Learner Engagement by Tool

\begin{tabular}{llll}
\hline & $F$ & $d f$ & $p$ \\
\hline Tool & 10.907 & 2,94 & $.001^{*}$ \\
\hline$* p<.05$ & & &
\end{tabular}

For situations involving three or more groups, when the null hypothesis is rejected, a multiple comparison procedure is needed to determine which means or combination of means are different (Lomax, 1992). Therefore, a post hoc was conducted on the repeated measure for instructional tool. Paired samples $t$ tests were utilized to determine whether there was a statistically significant difference between each pair of tools. As shown in Table 9 , there was a statistically significant difference between discussion board and e-mail, $t(318)$ $=-2.05, p<.042$; between e-mail and online chat, $t(99)=7.02, p<.001$; and between online chat and discussion board, $t(102)=6.42, p$ $<.001$. The mean of e-mail was higher than the mean of discussion board, while the mean of discussion board was higher than the mean of online chat. In Table 10, the descriptive analysis indicates that learners thought e-mail provided the highest learner engagement, followed by discussion board.

Table 9. Paired Samples $t$ Test among Three Tools for Learner Engagement

\begin{tabular}{lclll}
\hline Pairs & $\begin{array}{l}\text { Mean } \\
\text { Difference }\end{array}$ & $t$ & $d f$ & Sig. \\
\hline DB - EM & -.14 & -2.05 & 318 & $.042^{*}$ \\
DB - OC & .81 & 7.02 & 99 & $.000^{*}$ \\
EM - OC & .95 & 6.42 & 102 & $.000^{*}$ \\
\hline$* p<.05$ DB = Discussion Board; EM = \\
E-mail; OC = Online Chat
\end{tabular}


Table 10. Descriptive Analysis of Three Tools - Learner Engagement

\begin{tabular}{l|l|l|l|l}
\hline & & $M$ & $N$ & $S D$ \\
\hline \multirow{2}{*}{$\begin{array}{l}\text { Pair 1 } \\
\text { DB - EM }\end{array}$} & DB & 3.61 & 319 & 1.03 \\
\cline { 2 - 5 } & EM & 3.75 & 319 & .94 \\
\hline Pair 2 & BD & 3.72 & 100 & 1.03 \\
\cline { 2 - 5 } DB - OC & OC & 2.91 & 100 & 1.19 \\
\hline $\begin{array}{l}\text { Pair 3 } \\
\text { EM - OC }\end{array}$ & EM & 3.84 & 103 & .89 \\
\cline { 2 - 5 } & OC & 2.90 & 103 & 1.21 \\
\hline
\end{tabular}

$\mathrm{DB}=$ Discussion Board; $\mathrm{EM}=\mathrm{E}-\mathrm{mail} ; \mathrm{OC}=$ Online Chat

\subsection{Preference of Use of the Tools}

A four-factor split-plot ANOVA was applied to analyze the data. The questions in the instrument were repeated across each of the three tools (discussion board, e-mail, and online chat) in order to determine interaction efficacy in a Web-based environment. As shown in Table 11, there was a statistically significant difference across tools in terms of tool preference; in other words, the three tools had a differential influence on the learners' preferences, $F(2,140)=12.270, p<.05$. There was a statistically significant interaction between tools and learners' experiences, which indicated that tool preference varied based on prior online experience, $F(2,140)=2.633, p$ $<.05$.

Table 11. ANOVA Summary Table for Significant Effects on Preference of Tool Use by Tool and Experience

\begin{tabular}{lrll}
\hline & \multicolumn{1}{l}{$F$} & $d f$ & \multicolumn{1}{l}{$p$} \\
\hline Tool & 12.270 & 2,140 & $.000^{*}$ \\
Tool x Experience & 2.633 & 2,140 & $.009^{*}$ \\
\hline$* p<.05$ & & &
\end{tabular}

A post hoc test was performed using paired samples $t$ tests to determine which tools were significantly different from each other. As shown in Table 12, there was a significant difference between the means of discussion board and e-mail, $t(354)=-4.87, p<.001$; between e-mail and online chat, $t(144)=6.10, p<.001$; and between discussion board and online chat, $t(150)=7.93, p<.001$. The mean of e-mail was higher than the means of discussion board and online chat, while the mean of discussion board was higher than the mean of online chat.

Table 12. Paired Samples $t$ Test among Three Tools for The Preference of Tool Use

\begin{tabular}{cllll}
\hline Pairs & $\begin{array}{l}\text { Mean } \\
\text { Difference }\end{array}$ & $t$ & $d f$ & Sig. \\
\hline DB - EM & -.24 & -4.87 & 354 & $.000^{*}$ \\
DB - OC & .60 & 6.10 & 144 & $.000^{*}$ \\
EM - OC & .79 & 7.93 & 150 & $.000^{*}$ \\
\hline$* p<.05$ DB = Discussion Board; EM $=$ \\
E-mail; OC = Online Chat
\end{tabular}

Because of the significant interaction between experience level and tools, the data was analyzed to determine if (a) the instructional tool variable significantly interacted with each experience group, and (b) the experience variable significantly interacted with each instructional tool. There was a statistically significant difference between the three tools for learners who had no previous online experience, $F(2,56)=10.436, p<.05$. There was also a statistically significant difference between the three tools for learners whose experience included 1-2 online courses, $F(2,37)=27.147, p$ $<.05$. A third statistically significant difference was found between the three tools for learners whose experience included 3-4 online courses, $F(2,21)=5.416, p<.05$. However, there was no statistically significant difference between tools for learners whose experience included $5-6$ online courses, $F(2,7)=1.592, p>.05$ or for those whose experience included 7 or more online courses, $F(2,12)=.682, p>.05$.

Paired samples $t$ tests were performed to identify differences across the repeated measure 
in the group with no prior online experience. There was a statistically significant difference between discussion board and e-mail, $t(142)=$ -5.27, $p<.001$ and between e-mail and online chat, $t(61)=5.15, p<.001$. As shown in Table 13 , the descriptive analysis indicated that learners with no previous online experience preferred to use e-mail more than any other tool.

Table 13. Descriptive Analysis of Three Tools in Zero Experience Group

\begin{tabular}{l|l|l|l|l}
\hline & & $M$ & $N$ & $S D$ \\
\hline \multirow{2}{*}{$\begin{array}{l}\text { Pair 1 } \\
\text { DB - EM }\end{array}$} & DB & 3.79 & 143 & .85 \\
\cline { 2 - 5 } & EM & 4.20 & 143 & .63 \\
\hline \multirow{2}{*}{$\begin{array}{l}\text { Pair 2 } \\
\text { DB - OC }\end{array}$} & BD & 3.79 & 58 & .92 \\
\cline { 2 - 5 } & OC & 3.55 & 58 & .74 \\
\hline \multirow{2}{*}{$\begin{array}{l}\text { Pair 3 } \\
\text { EM - OC }\end{array}$} & EM & 4.14 & 62 & .60 \\
\cline { 2 - 5 } & OC & 3.52 & 62 & .74 \\
\hline
\end{tabular}

$\mathrm{DB}=$ Discussion Board; EM $=$ E-mail; $\mathrm{OC}=$ Online Chat

In regard to learners whose experience included 1-2 online courses, there was a statistically significant difference between discussion board and online chat, $t(38)=6.71$, $p<.001$ and between e-mail and online chat, $t(40)=6.70, p<.001$. As shown in Table 14, the descriptive analysis indicates that learners in this group preferred to use e-mail and discussion board more than online chat.

In regard to learners whose experience included 3-4 online courses, there was a statistically significant difference between discussion board and online chat, $t(23)=3.14$, $p<.005$ and between e-mail and online chat, $t(23)=2.56, p<.018$. Again, as shown in Table 15 , the descriptive analysis indicated that learners in this group preferred to use e-mail and discussion board more than online chat.
The data was also analyzed using a univariate method. There was a statistically significant difference between experience levels and discussion board preference, which indicated that learners from different experience groups felt differently about discussion board use, $F(1,357)=3.043, p<.05$. However, there was no statistically significant difference between e-mail $[F(1,413)=1.258, p>.05]$ or online chat $[F(1,146)=2.048, p>.05]$ according to experience level.

Table 14. Descriptive Analysis of Three Tools in 1-2 Experience Group

\begin{tabular}{l|l|l|l|l}
\hline & & $M$ & $N$ & $S D$ \\
\hline Pair 1 & DB & 4.03 & 107 & .92 \\
\cline { 2 - 5 } DB - EM & EM & 4.15 & 107 & .73 \\
\hline Pair 2 & BD & 4.17 & 39 & .83 \\
\cline { 2 - 5 } DB - OC & OC & 3.00 & 39 & 1.08 \\
\hline Pair 3 & EM & 4.37 & 41 & .64 \\
\cline { 2 - 5 } EM - OC & OC & 3.03 & 41 & 1.10 \\
\hline
\end{tabular}

$\mathrm{DB}=$ Discussion Board; $\mathrm{EM}=\mathrm{E}-\mathrm{mail} ; \mathrm{OC}=$ Online Chat

Table 15. Descriptive Analysis of Three Tools in 3-4 Experience Group

\begin{tabular}{l|l|l|l|l}
\hline & & $M$ & $N$ & $S D$ \\
\hline \multirow{2}{*}{$\begin{array}{l}\text { Pair 1 } \\
\text { DB - EM }\end{array}$} & DB & 4.21 & 54 & .76 \\
\cline { 2 - 5 } & EM & 4.28 & 54 & .61 \\
\hline Pair 2 & BD & 4.20 & 24 & .78 \\
\cline { 2 - 5 } DB - OC & OC & 3.38 & 24 & 1.23 \\
\hline \multirow{2}{*}{$\begin{array}{l}\text { Pair 3 } \\
\text { EM - OC }\end{array}$} & EM & 4.13 & 24 & .79 \\
\cline { 2 - 5 } & OC & 3.35 & 24 & 1.20 \\
\hline
\end{tabular}

$\mathrm{DB}=$ Discussion Board; $\mathrm{EM}=$ E-mail; $\mathrm{OC}=$ Online Chat

A post hoc test was performed to identify which of the five experience groups were significantly different from each other in terms of tool preference. Learners who had no experience were less in favor of discussion 
board use than learners whose experience included 3-4 courses, $p<.012$. There were no statistically significant differences between any other pairs of groups based on experience.

\section{Discussion}

The results of this study support previous findings and also suggest potential new explanations regarding learner interaction in Web-based courses. In regard to instructional design, learners in general thought they gained a higher amount of interaction using e-mail than they did using a discussion board or online chat. Younger learners in particular thought they received a high amount of learning interaction through e-mail, while older learners did not think the three tools had a differential effect on their learning interaction. This supports one previous finding that e-mail encouraged learners to contact, and interact with, the instructor and other students, as well as fostered an environment in which students could participate and reflect upon their thoughts (Mount Royal College, 2003).

In regard to instructor engagement, learners in general thought they had higher engagement with their instructors by using e-mail and discussion board. Younger learners in particular perceived that they received higher instructor engagement through e-mail and discussion board, while older learners did not think the three tools had a differential effect on instructor engagement. Interestingly,e-mailanddiscussion board have been described as valuable for information exchanges in an asynchronous format by providing opportunities for shy or non-native speakers to express themselves (Delahoussaye \& Neiheisel, 2005; Funaro \& Montell, 1999).

In regard to learner engagement, learners thought they had higher engagement with their peers by using e-mail and discussion board.
However, no significant differences were found according to gender, age, or prior online learning experience, which concurs with the current literature (Davidson-Shivers, Tanner, \& Muilenburg, 2000; Funaro \& Montell, 1999).

In regard to instructional tool preference, learners preferred to use e-mail and discussion board over online chat. Specifically, learners with no online experience preferred to use e-mail, and learners whose experience included one to four courses preferred to use e-mail and discussion board. Learners with significant online course experience (five or more courses) appeared to consider all the tools equally preferable. This corroborates previous findings that online learning experience is an important factor for learners to succeed in the use of a variety of Web-based applications (Hannafin, Hill, Oliver, Glazer, \& Sharma, 2003).

A flexible timeframe is a major advantage of a Web-based course. Within this flexible timeframe, Davidson-Shivers et al. (2000) state that online chats provide direct realtime learning environments involving a high degree of interaction. However, the findings in this study indicate that online chat was the least favorite tool among online learners. One possible reason for this is that online chat requires synchronous communication between instructors and learners. Driscoll (1998) suggests that asynchronous methods provide a more flexible timeframe for students to reflect on what they have learned as compared to synchronous delivery formats. If the student is required to be online at a specific time and day to participate in a chat session, this is counterproductive to Martinez's " anywhere, anytime, just-enough needs of the learner" (2002, p. 168) description of the online learning experience. This may very well account for the lack of enthusiasm for this tool. 


\section{Implications}

Important to acknowledge is that the limited sample size and/or the snowball sampling method could influence the generalizability of this study's results to other distance education formats. Still, several practice implications can be inferred from the findings.

First, the incorporation of e-mail into all Web-based course designs should certainly be considered. According to this study, online learners thought e-mail provided higher interaction, higher instructor engagement, and higher peer engagement; they also thought e-mail was a preferable tool for Web-based learning. Carswell, Thomas, Petre, Price, and Richards (2000) suggest that e-mail forwarding effectively brings the latest course postings to students' attention. Even though alternative delivery formats are available, such as a discussion board, students prefer e-mail simply due to the convenience of e-mail access. College students utilize e-mail a great deal. For instance, at one Midwestern university, a study of student usage of online resources showed that $99 \%$ of students used e-mail and $93 \%$ used Blackboard/WebCT, which includes an e-mail function (Janz, Owen, \& Ande, 2005).

Second, the transactional distance should be shortened between instructors and learners in a Web-based environment. Moore (1991) defined transactional distance in terms of dialogue and communication between instructors and learners and suggested that transactional distance increases if dialogue decreases. Prompt e-mail response is one way to reduce the "transactional distance" between instructors and learners. However, in order to provide a constructive learning environment, instructors could use strategies such as asking open-ended questions and encouraging students to reply with more personal thought to ensure that the e-mail dialogue is interactive rather than just a one-way instruction.

\section{Future Research}

The results of this study would suggest several directions for future research. First, because older learners did not perceive that the three tools provided as much interaction as the younger learners, a further exploration into how age and/or generational differences might impact the perceptions of Web-based learners is applicable.

Second, the age range of 18-29 may have been too broad to determine if the participants were undergraduate or graduate students. Future research could break the age ranges into smaller scales to achieve more specific results and determine whether differences exist between undergraduate and graduate populations relative to perceived amounts of interaction.

Third, the study found that prior online experience impacted tool preference. Future research could focus on the characteristics of different tools within Web-based applications to determine the reasons for these differences in preferences.

Fourth, future research could explore the relationship between instructional tools and learner characteristics. For example, could factors such as visual, auditory, kinesthetic, or environmental learning styles impact the interaction potential of Web-based instructional tools? The findings could benefit Web-based instructors who use different Learning Content Management Systems such as Blackboard and WebCT.

Finally, future research could investigate what kinds of learning interaction online learners are seeking from their learning peers. In this study, no statistical interaction was found among the variables in regard to learner engagement. Future research could 
revisit this issue to help Web-based instructors understand what their students want from their learning partners and how instructors might better design their courses in order to facilitate student involvement in a computer-mediated environment.

\section{Conclusion}

Distance education, particularly the Webbased online format, is increasing at a rapid pace. By the fall of $1998,90 \%$ of all institutions with enrollments of 10,000 or more students, and $85 \%$ of those with 3,000 or more students, offered distance education courses (Gibson, 1998). This growth is due in part to increased technology access and ease of technology tool use (Smallwood \& Zargari, 2000). As more Web-based courses are offered, providing the interaction among learners, instructors, and the interactive tools/technology is needed.

In this study, three interactive tools (discussion board, e-mail, and online chat) significantly interacted with one another across four different factors: Instructional Design, Instructor Engagement, Learner Engagement, and Tool Preference. However, the age, gender, and prior online experience of the learners did not yield consistent results within these four factors. The findings in this study should urge instructors to reevaluate their online course designs and more effectively manage their online courses.

Every day, more and more learners take advantage of the flexibility and convenience of Web-based distance education. Every professional educator has the privilege and duty to maintain the instructional best practices that already exist in Web-based learning, as well as to develop newer and even better learning environments for their students.

\section{References}

Aggarwal, A. (2000). Web-based education. In A. Aggarwal (Ed.), Web-based learning and teaching technologies: Opportunities and challenges (pp. 2-16). Hershey, PA: Idea Group Publishing.

Becker, J. (2001). Teaching technology today: A delivery, preparation, \& mastering approach. WebNet Journal, 3(3), 15-19.

Campbell, D. T., \& Stanley, J. C. (1966). Experimental and quasi-experimental designs for research. Chicago: Rand McNally.

Carlson, R., \& Repman, J. (2000). Building that human touch into your web-based course. WebNet Journal, 2(3), 9-11.

Carswell, L., Thomas, P., Petre, M., Price, B., \& Richards, M. (2000). Distance education via the internet: The student experience. British Journal of Educational Technology, 31(1), 29-46.

Cherulnik, P. D. (1983). Behavioral research: Assessing the validity of research findings in psychology. New York: Harper \& Row.

Creswell, J. W. (2005). Educational research: Planning, conducting, and evaluating quantitative and qualitative research $\left(2^{\text {nd }}\right.$ ed.). Upper Saddle River, NJ: Pearson Education.

Davidson-Shivers, G., Tanner, E., \& Muilenburg, L. (2000). Online discussion: How do students participate? New Orleans, LA: AmericanEducational Research Association. (ERIC Document Reproduction Service No. ED443410)

Delahoussaye, C., \& Neiheisel, M. (2005). Webbased web-enhanced curriculum. Retrieved April 9, 2005, from http://www.celt.lsu.edu/ CFD/E-Proceedings/ WEB-BASED $\% 20$ WEB-ENHANCED\%20CURRICULUM. htm

Dewey, J. (1916). Democracy and education. New York: The Macmillan Company.

Funaro, G., \& Montell, F. (1999). Pedagogical 
roles and implementation guidelines for online communication tools. ALN magazine, 3(2). Retrieved April 10, 2005, from http:// www.aln.org/alnweb/magazine/Vol3 issue2/funaro.htm

Gibson, C. (1998). The distance learner's academic self-concept. In C. Gibson (Ed.), Distance learners in higher education: Institutional responses for quality outcomes (pp. 47-64). Madison, WI: Atwood Publishing.

Glasow, P. (2005, April). Fundamentals of survey research methodology. Retrieved January 16, 2009 from http://www. mitre.org/work/tech_papers/tech papers_05/05_0638/05_0638.pdf

Hannafin, M., Hill, J. R., Oliver, K., Glazer, E., \& Sharma, P. (2003). Cognitive leaning factors in web-based distance learning environments. In M. G. Moore \& W. G. Anderson (Eds.), Handbook of distance education (pp. 245-260). Mahwah, NJ: Lawrence Erlbaum Associates.

Janz, K., Owen, S., \& Ande, T. (2005). Indiana State University Technology Profile 2005. Terre Haute, IN Retrieved December 21, 2005, from http://www.indstate.edu/oit/irts/ pt3/pubs/profile/Tech\%20Profile 2005.pdf

Lomax, R. (1992). Statistical concepts: A second course for education and the behavioral sciences. White Plains, NY: Longman Publishing Group.

Martinez, M. (2002). Designing learning objects to personalize instruction. In D. A. Wiley (Ed.), The instructional use of learning objects (pp. 151-171). Bloomington, IN: AIT/AECT.

Moore, M. (1991). Editorial: Distance education theory. The American Journal of Distance Education, 5(3), 1-6.

Moore, M., \& Kearsley, G. (2005). Distance education: A systems view ( $2^{\text {nd }}$ ed.). Belmont, CA: Thomson Wadsworth.

Mount Royal College. (2003). VCLT online: Student support: Introduction to learning online. Retrieved April 9, 2005, from http:// www.mtroyal.ca/ADC/teachingonline/ student_internetguidetechtools.htm

Prensky, $\bar{M}$. (2001). Digital natives, digital immigrants. On the Horizon, 9(5), 1-5.

Roblyer, M. D., \& Ekhaml, L. (2000). How interactive are your courses? A rubric for assessing interaction in distance learning. Online Journal of Distance Learning Administration 3(2). Retrieved September 7, 2009, from http://www.westga. edu/ distance/roblyer32.html

Roblyer, M., \& Wiencke, W. (2003). Design and use of a rubric to assess and encourage interactive qualities in distance courses. The American Journal Distance Education, 17(2), 77-98.

Ruhleder, K., \& Twidale, M. (2000). Reflective collaborative learning on the web: Drawing on the master class. Retrieved June, 9, 2005,

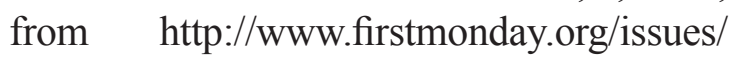
issue 5 5/ruhleder/index.html

Smallwood, J. E., \& Zargari, A. (2000).The development and delivery of a distance learning(DL) course in industrial technology. Journal of Industrial Technology, 16(3), 2-4.

Survey Methods. (1999). University of Texas Libraries. Retrieved January; 16, 2009 from http://www.ischool.utexas.edu/ palmquis/ courses/survey.html\#TOP

Tuckman, B. (2002, August). Academic procrastinators: Their rationalizations and web-based performance. Paper presented at the Annual Meeting of American Psychological Association, Chicago, IL.

Vygotsky, L. (1978). Mind in society: The developmentofhigherpsychologicalprocess. Cambridge, MA: Harvard University Press.

\section{Contact the Author}

Ching-Wen Chang, Ph.D.

Missouri State University, USA

E-mail: cchang@missouristate.edu 


\section{APPENDIX A: Effectiveness of Interaction in Distance Learning Course Questionnaire}

Please answer this questionnaire for only ONE web-based course; either one you are currently enrolled in, or one you have taken in the past.

\section{Demographic Data Questions}

1. Please indicate your gender. Female Male

2. So far, how many courses have you completed online? 0 1-2 3-4 5-6 $7+$

3. Please indicate your age. 18-29 $30-39 \quad 40-49 \quad 50-59 \quad 60+$

4. Please indicate your major.

5. Please indicate your school.

\section{Instructional design for interaction}

6. Please indicate your agreement with the following statements:

\begin{tabular}{|l|l|l|l|l|l|l|}
\hline & $\begin{array}{l}\text { Strongly } \\
\text { agree }\end{array}$ & Agree & $\begin{array}{l}\text { Neither agree } \\
\text { nor disagree }\end{array}$ & Disagree & $\begin{array}{l}\text { Strongly } \\
\text { disagree }\end{array}$ & $\begin{array}{l}\text { Never } \\
\text { used }\end{array}$ \\
\hline $\begin{array}{l}\text { The amount of interaction with } \\
\text { Discussion Board is high. }\end{array}$ & & & & & & \\
\hline $\begin{array}{l}\text { The amount of interaction with } \\
\text { E-mail is high. }\end{array}$ & & & & & & \\
\hline $\begin{array}{l}\text { The amount of interaction with } \\
\text { Online Chat is high. }\end{array}$ & & & & & & \\
\hline
\end{tabular}

\section{Instructor Engagement}

7. How soon do/did you get response from or instructor using the following tools?

\begin{tabular}{|l|l|l|l|l|l|l|}
\hline & $\begin{array}{l}\text { Within 24 } \\
\text { hours }\end{array}$ & $\begin{array}{l}\text { Within 48 } \\
\text { hours }\end{array}$ & $\begin{array}{l}\text { Within } \\
72 \text { hours }\end{array}$ & $\begin{array}{l}\text { Within a } \\
\text { week }\end{array}$ & $\begin{array}{l}\text { Never } \\
\text { used }\end{array}$ & \\
\hline Discussion Board & & & & & & \\
\hline E-mail & & & & & & \\
\hline Online Chat & & & & & &
\end{tabular}

8. How much interaction do/did you get from your instructor using the following tools?

Please use the key below for your responses:

$5=$ Responses provided detailed analysis to all students with additional information to support learning

$4=$ Responses provided detailed analysis to all students

$3=$ Responses provided some analysis to all students

$2=$ Responses provided some analysis to most students

$1=$ Responses provided little or no analysis to random students

$0=$ Never used this too

\begin{tabular}{|l|l|l|l|l|l|l|}
\hline & 5 & 4 & 3 & 2 & 1 & 0 \\
\hline Discussion Board & & & & & & \\
\hline E-mail & & & & & & \\
\hline Online Chat & & & & & & \\
\hline
\end{tabular}

\section{Learner Engagement}

9. Within one course, how often are you required by syllabus to use the following tools?

\begin{tabular}{|l|l|l|l|l|l|l|}
\hline & $\begin{array}{l}\text { Very } \\
\text { Frequently }\end{array}$ & Frequently & Sometimes & Seldom & $\begin{array}{l}\text { Very } \\
\text { Seldom }\end{array}$ & Never used \\
\hline Discussion Board & & & & & & \\
\hline
\end{tabular}




\begin{tabular}{|c|c|c|c|c|c|c|}
\hline E-mail & & & & & & \\
\hline Online Chat & & & & & & \\
\hline 10. How often do & bu use the & ollowing & tools to reply tc & questions? & & \\
\hline Discussion Board & & & & & & \\
\hline E-mail & & & & & & \\
\hline Online Chat & & & & & & \\
\hline 11. How often do & u use the & ollowing & tools to initiate & questions? & & \\
\hline Discussion Board & & & & & & \\
\hline E-mail & & & & & & \\
\hline Online Chat & & & & & & \\
\hline Preference of the & ools & & & & & \\
\hline $\begin{array}{l}\text { 12. My preference } \\
\text { tools? }\end{array}$ & if the instru & ctor doe & did not specify & would be & use which & the following \\
\hline & $\begin{array}{l}\text { Strongly } \\
\text { agree }\end{array}$ & Agree & $\begin{array}{l}\text { Neitheragree } \\
\text { nor disagree }\end{array}$ & Disagree & \begin{tabular}{|l|}
$\begin{array}{l}\text { Strongly } \\
\text { disagree }\end{array}$ \\
\end{tabular} & Never used \\
\hline Discussion Board & & & & & & \\
\hline E-mail & & & & & & \\
\hline Online Chat & & & & & & \\
\hline 13. Which of the $f$ & lowing toc & ls provic & es the most mea & ningful inte & action? & \\
\hline Discussion Board & & & & & & \\
\hline E-mail & & & & & & \\
\hline Online Chat & & & & & & \\
\hline 14. Which of the $f$ & lowing toc & 1s enhan & e learning the $n$ & nost? & & \\
\hline Discussion Board & & & & & & \\
\hline E-mail & & & & & & \\
\hline Online Chat & & & & & & \\
\hline 15. Which of the $f$ & lowing toc & ls provic & the most helpf & ul feedback & analysis? & \\
\hline Discussion Board & & & & & & \\
\hline E-mail & & & & & & \\
\hline Online Chat & & & & & & \\
\hline 16. Which of the $f$ & lowing toc & ls is the & nost effective at & building $\mathrm{cc}$ & laboration & \\
\hline Discussion Board & & & & & & \\
\hline E-mail & & & & & & \\
\hline Online Chat & & & & & & \\
\hline
\end{tabular}

NOTE: The questionnaire used in this research was an online web form; the above document approximates the appearance of the actual document. 